\title{
Key Success Factors of Blockchain Platform for Micro-enterprises
}

\author{
Mei-Hsiang YANG ${ }^{1}$, Tzong-Ru LEE ${ }^{2}$, Tin-Chang CHANG ${ }^{3}$ \\ Received: May 8, 2019 Revised: May 9, 2019 Accepted: June 14, 2019
}

\begin{abstract}
The purposes of the study are threefold: (1) develop key successful factors of blockchain platform for micro-enterprises based on Balanced Scorecard (BSC), (2) find out the correlation between the key successful factors of blockchain platform for micro-enterprises, and (3) understand the perception of micro-enterprise blockchain and the difference between theoretical guidance and practical application. This study combines Interpretative Structural Modeling Method, (ISM) and Decision-Making Trial and Evaluation Laboratory (DEMATEL) to analyze the causal relationships and hierarchical structures of the 12 key successful factors of blockchain platform for micro-enterprises and understand the correlation between factors. The 12 key successful factors developed based on the four perspectives of the Balanced Scorecard, and the questionnaire designs based on the concept of DEMATEL, and then analyzed data by DEMATEL and ISM methods to understand the correlation between key factors. The research results show that the key successful factors of blockchain platform for microenterprises include "brand equity", "security and anti-counterfeiting", "sales growth", "transparency and clear", "trust", "consensus mechanism", "traceability", "consistency", "tracking", "innovation management", "international", "organizational adaptation", in which consumer "trust" plays an important role. Micro-enterprises can use blockchain to expand the market, provide customers with better service quality, and bring sales growth to micro-enterprises.
\end{abstract}

Keywords: Micro-enterprise, Blockchain, Balanced Scorecard, ISM, DEMATEL.

JEL Classification Code: D47, M10, M21.

\section{Introduction}

Since 1981, the micro-enterprises have maintained more than $70 \%$ of Taiwan's economic system and highlighted its importance in the industrial supply chain. The number of micro-enterprises is highly correlated with nations, economics, and lives issues (Wang, 2011). However, the

1 First Author. Ph.D. Student, Department of Business of Administration, Asia University, Taiwan [Postal Address: No. 33, Ln. 236, Sector 1, Meicun Road, West District, Taichung City 403, Taiwan (R.O.C.)]. Email: a0920901123@gmail.com

2 Corresponding Author. Professor, Marketing Department, National Chung Hsing University, Taiwan [Postal Address: 145 Xingda Road, South District, Taichung City 402, Taiwan (R.O.C.)] Email: trlee@dragon.nchu.edu.tw

3 Associate Professor, Department of Digital Media Design, Department of Business of Administration, Asia University, Taiwan. Email: ervince@asia.edu.tw

(c) Copyright: Korean Distribution Science Association (KODISA)

This is an Open Access article distributed under the terms of the Creative Commons Attribution NonCommercial License (https://creativecommons.org/licenses/by-nc/4.0/) which permits unrestricted noncommercial use, distribution, and reproduction in any medium, provided the original work is properly cited. development of micro-enterprises has many concerns and challenges and it faces "a small amount of capital and a weak constitution". Micro-enterprises have faced the lacks of marketing concept and insufficient resources, which is not conducive to their grasp of market information dynamics (Wang, 2011; Hsu \& Huang, 2011) that is difficult for most microenterprises to operate for a long-term.

Chang (2003) mentioned that if mirco-enterprises can share the data with one another through blockchain, the micro-enterprises can lower costs and improve the production activities to open up markets for enterprises and attract more consumers. Since the application of microenterprise blockchain has not yet been established, this study has utilized the development of blockchain in financial markets, and the characteristics of unchangeable, decentralized, trustworthy and consistent in micro-enterprise management to improve the competitiveness of microenterprises. The research results will be the reference for the management and development of micro-enterprises.

The micro-enterprises in Taiwan have been taken as the research subject, aiming at constructing the system of 
micro-enterprise blockchain, and finding out the key success factors for blockchain, and analyzing the correlation between factors to assist enterprises to introduce the blockchain innovation technology. In developing economies, micro-enterprises not only create employment opportunities, but also play an important role in industrial development and economic development. In addition, micro-enterprises lack credit and international activities include exports and also other processes that promote the learning process (Trinh \& Doan, 2018). Although the total number of enterprises is many, researches on micro-enterprises are rare, and it often underestimates the role and the importance of microenterprises in the economy, and it is difficult to obtain reliable data on micro-enterprises. To solve the problems of micro-enterprises lack the funds and information is not transparent, BSC-DEMATEL-ISM is used to find the problems and make micro-enterprise transparent and enhance visibility.

Therefore, the purposes of this research are: (1) based on literature review to find the 12 factors, Balanced Scorecard (BSC) to 12 key success factors affecting the blockchain by micro-enterprises; (2) Through Interpretative Structural Modelling Method (ISM) and Decision-Making Trial and Evaluation Laboratory (DEMATEL) to find the correlation between the key success factors of micro-enterprise blockchain platform; (3) based on the research results to understand the points of view of micro-enterprises on the blockchain, and distinguish the difference between theoretical guidance and practical application.

\section{Literature Review}

\subsection{Micro-Entreprise}

\subsubsection{The Definition of Micro-entreprise}

At present, there are several definitions of microenterprises, but the most of which are defined by the number of employees or the amount of capital. The Association for Enterprise Opportunity (AEO) defines a micro-enterprise with less than 5 employees or the capital of the business is less than $\$ 35,000$; Organization for Economic Co-operation and Development (OECD) pointed out that enterprises with less than 20 employees are microenterprises; the International Labor Office (ILO) points out that the micro-enterprises business is less than 5 people, and no more than 10 people as standards. Other international development organizations, such as The European Union (EU) and the Asia-Pacific Economic Cooperation (APEC) are based on the number of employees of 10 or less as the standard for micro- enterprises and small businesses (Hsu \& Huang, 2011). In addition, Chin and Nor (2016) point out that there are many problems and challenges in the development of microenterprises, such as lack of marketing concepts and insufficient resources; therefore, micro-enterprises needs supports in different aspects development.

In Taiwan, Article 3 of the "Small and Medium Enterprises Criteria" issued by the Ministry of Economic Affairs (2015) states that small-scale enterprises employ less than five employees in SMEs, and Ministry of Labor (2007) define the micro-enterprise is as a business with less than 5 employees. The definition of micro-enterprises stated above that the micro-enterprises in Taiwan government has used is the "business with less than five employees".

\subsubsection{The Dilemma Micro-enterprises Faced in Taiwan}

Micro-enterprise structure and physical fitness in Taiwan are not as good as the large-scale enterprises (Chen \& Tsai, 2012). Although micro-enterprises can balance the gap between the urban and rural, create employment opportunities, agglomerate social networks and promote income equalization, the financial constraints are often encountered when raising follow-up operating funds (Wang, 2011). In addition, Chen and Tsai (2012) mention that the minor and micro-enterprises have low financial statements credibility, and the internal and external accounts often have inconsistencies, and it is difficult to reflect the risk situation in enterprises. On the other hand, some studies also point out that micro-enterprises have no formal organization, lack of management systems, formal financing channels, fixed capitals, and the sales models are mainly based on the local markets. The production operation lacks quality management. The company's ability to resist risks is low (Wang \& Wang, 2011).

Therefore, micro-enterprises can be assisted to establish marketing network and shopping platform certification, establish information sharing platform, upgrade and transformation, and participate in entrepreneurship is the key for micro-enterprises to survival (Wang, 2011).

\subsection{Blockchain}

Blockchain is a shared digital ledger that is maintained by a group of nodes not fully trusted by each other (Dinh, Wang, Chen, Liu, Ooi, \& Tan, 2017). Anyone can participate in the consensus process and add blockchains to the chain (Pilkington, 2016). The blockchain data is permanently recorded in the form of files (Wang, Zha, Ni, Liu, Guo, Niu, \& Zheng, 2019). The stored data is randomly randomized and each block contains the hash values of the previous block (Li, Tian, Zhang, \& He, 2019; Tian, Li, Qiu, Sun, \& Su, 2019; 
Shrestha, Bajracharya, Shrestha., \& Nam, 2019; Buehrer, Senecal, \& Pullins, 2005). These records are called blocks. Each timestamp will be included in the random hash value of the previous timestamp, so each timestamp is also enhanced to the previous timestamp; traceback mechanism to ensure all data stored in the blockchain is confirmed and tracked (Ko, 2019; Abeyratne \& Monfared, 2016; Larimer, 2014). In this way, the blockchain network can be connected from the first block to the current block, as if a long chain is connected to each other before and after (Wolcot, Qureshi, \& Kamal, 2007; Ziyae, Sajadi, \& Mobarak, 2014; Lee \& Chen, 2017).

In the technology concept of blockchain, it has the characteristics of high credibility, security, and confidentiality, and it is safe, transparent, stable, auditable, and highly efficient record information (Choi, Seol, Lee, Cho, \& Park, 2008; Buck, 2017; Yang \& Tso, 2018; Alibasa, 2019). Blockchain technology is also a subversion and innovation of traditional digital technology (Romano \& Schmid, 2017; Hany, Atlam, \& Wills, 2018). It uses distributed decentralized book technology to store, verify, transmit and communicate network data through the nodes, and uses cryptography to record the fund flow structural (Muzammal, Qu, \& Nasrulin, 2019). At present, the application of blockchain has been extended to the fields of Internet of Things (loT), intelligent manufacturing, supply chain management, and digital asset trading (Huang, 2011; Yang \& Tso, 2018; Taylor, Dargahi, Dehghantanha, Parizi, \& Choo, 2019; Pla-Barber \& Alegre, 2014; Lee \& Chen, 2017; Viriyasitavat \& Hoonsopon, 2019).

\subsection{BSC}

BSC is a complex performance appraisal system that evaluates organizational performance by four perspectives, financial perspective, customer perspective, learning growth perspective and internal perspective (Patil \& Kant, 2016; Basso, Casarin, \& Funari, 2018). It is also a strategic management tool introduced by Kaplan and Norton in 1996. Organizational performances and effective strategies are the challenges for business management. BSC is designed to balance financial and non-financial, as well as past and future performance assessment tools, for companies responding quickly in a competitive environment.

The organization's operational activities select the best strategy and indicator interactions by BSC, as well as assign the weights, prioritize and determine the best options (Modak, Ghosh, \& Pathak, 2018). BSC relies on the four perspectives that are connected together by causality to form a system. BSC emphasizes the linkage among the strategies, actions, and outcomes, primarily to establish key quantitative information systems and successful variables; and then BSC-DEMATEL-ISM applies in the microenterprise blockchain platform for empirical analysis (Patil \& Kant, 2016; Basso, Casarin, \& Funari, 2018; Acuña-Carvajal, Pinto-Tarazona, López-Ospina, Barros-Castro, \& Palacio, 2019; Lin, Lee, Chao, \& Chang, 2010).

BSC transforms the organization's visions and strategies into measurable, specific, and strategic indicators. It is combined Interpretation Structure Model (ISM) and Decision-Making Trial and Evaluation Laboratory (DEMATEL) is used as an SME International. Tools for helping minor and micro-enterprises to improve performance transform into international enterprises (Lee \& Chen, 2017).

ISM analyzes the impact factors by hierarchical analysis and establishing a multi-level structure of impact factors to guide the relevant department. ISM is used in this study is to determine the factors from organizations and consumers' perspectives (Kumar \& Dixit, 2018). In addition, ISM illustrates the intricate interrelationships and divides into four categories, autonomic factor, dependence factor, linage factors, and driving factor).

DEMATEL is used when the decision making and assessment are in fuzzy situations and to identify interactions and prioritze the factors (Kumar \& Dixit, 2018; Addae, Zhang, Zhou, Fandi, \& Wang, 2019). Finally, selecting important relationships are sufficient to be considered in the impact-relation (Quezada, López-Ospina, Palominos, \& Oddershede, 2018).

This study is based on four perspectives, financial perspective, customer perspective, learning growth perspective and internal perspectives to develop 12 key success factors of blockchain platform for micro-enterprise and combined with ISM and DEMATEL to provide the opportunities for micro-enterprises successfully.

\subsection{Success Factors of Micro-enterprise Blockchain}

Based on the literature review, 12 key success factors, "brand equity", "security anti-counterfeiting", "sales growth", "transparency and clear", "trust", "consensus mechanism", "traceability", "consistency" and "tracking", "innovation management", "international", and "organization adaptation" affect the micro-enterprises blockchain, and 12 factors are divided into financial perspective, customer perspective, learning growth perspective and internal perspective, shown in Table 1. The 12 factors are used as the content for this research development questionnaire and further researches. 
Table 1: The factors of platform to make successful

\begin{tabular}{|c|c|c|}
\hline Literature Review & Factors & Perspectives \\
\hline Huang (2011); Choi et al. (2008); Taylor et al. (2019) & S1 Brand equity & \multirow{3}{*}{$\begin{array}{l}\text { Financial } \\
\text { perspective }\end{array}$} \\
\hline Yang and Tso (2018); Wang et al. (2019); Alibasa (2019); Buck (2017) & S2 Security anti-counterfeiting & \\
\hline $\begin{array}{l}\text { Buehrer et al. (2005); Li, Tian, Zhang and He (2019); Tian, Li, Qiu, Sun and Su } \\
\text { (2019); Shrestha et al. (2019) }\end{array}$ & S3 Sales growth & \\
\hline Wang et al. (2019); Li, Tian, Zhang and He (2019) & S4 Transparency and clear & \multirow{3}{*}{$\begin{array}{l}\text { Customers } \\
\text { perspective }\end{array}$} \\
\hline Tian, Li, Qiu, Sun and Su (2019); Shrestha et al. (2019) & S5 Trust & \\
\hline $\begin{array}{l}\text { Dinh, Wang, Chen, Liu, Ooi and Tan (2017); Pilkington (2016); Li, Tian, Zhang and } \\
\mathrm{He}(2019)\end{array}$ & S6 Consensus mechanism & \\
\hline Ministry of Economic Affairs, R.O.C. (2015); Wang et al. (2019) & S7 Traceability & \multirow{3}{*}{$\begin{array}{c}\text { Internal } \\
\text { Processes } \\
\text { perspective }\end{array}$} \\
\hline Ko (2019); Wang et al. ( 2019) & S8 Consistency & \\
\hline Abeyratne and Monfared (2016); Larimer(2014) & S9 Tracking & \\
\hline Romano and Schmid (2017); Hany et al. ( 2018) & S10 Innovation management & \multirow{3}{*}{$\begin{array}{l}\text { Learning } \\
\text { growth } \\
\text { perspective }\end{array}$} \\
\hline $\begin{array}{l}\text { Wolcot, Qureshi and Kamal (2007); Ziyae, Sajadi and Mobarak (2014);Lee and } \\
\text { Chen (2017) }\end{array}$ & S11 International & \\
\hline $\begin{array}{l}\text { Pla-Barber and Alegre (2014); Muzammal, Qu and Nasrulin (2019); Viriyasitavat } \\
\text { and Hoonsopon (2019) }\end{array}$ & S12 Organization adaptation & \\
\hline
\end{tabular}

\section{Research Methods}

\subsection{DEMATEL and ISM}

\subsubsection{DEMATEL}

DEMATEL was the first analysis method used by Gabus and Fontela in 1973 to solve complex global issues, such as famine, racial, environmental protection, etc. At present, the research scope of DEMATEL is quite extensive. Tsai (2018) believes that the high-tech industry relies heavily on R\&D personnel, and how to reduce the turnover rate of R\&D personnel is a problem for the high-tech industry. Therefore, DEMATEL is used to obtain a causal map that affects employee satisfaction, and the results of "reward", "promotion", "supervisor" and "job functions" are the main factors for solving the problem.

The small sample data can be analyzed by DEMATEL, but it must be confirmed the core problem and use the "matrix" method to present the relationship between the factors. The five values of "0", "1", "2", "3", and "4" are used to represent the values between the factors that express the degree of influence between the factors (Lee \& Chen, 2017).

\subsubsection{ISM}

ISM is used to solve and analyze complex situational problems, proposed by Warfield in 1973. The interpretative structure model mainly uses graphic as well as words. It can turn the complicated and disorderly factors into an orderly system and clarify the correlation between various factors (Jharkharia \& Shankar, 2004).

Kuo, Ma, Huang, Hu, and Huang (2010) analyzed the uncertain risks and challenges that enterprises may face when implementing a product service system (PSS), and the possible challenges are divided into multi-level structures. This study combines ISM and DEMATEL to analyze the causal relationships and hierarchical structures of the 12 key success factors of blockchain platform for micro-enterprises and understand the correlation between factors. ISM is used to establish a hierarchy to illustrate the interrelationships, and DEMATEL are set to find out the interactions the prioritizing factors in fuzzy environment.

\subsection{Questionnaire Design}

The 12 key success factors developed based on the four perspectives of BSC, and the questionnaire designs based on the concept of DEMATEL, and then analyzed data by DEMATEL and ISM methods to understand the correlation between key factors. The questionnaire is divided into three parts; the first part is the description of the factors of blockchain platform for micro-enterprise. The second part is to fill in the influence degree between the two factors. The 12 key factors are used to compare the two pairs that influence between the factors. The scale can be divided into five levels. "0", "1", "2", "3" and "4" represent "no influence" and "low influence", "Medium influence", "high influence" and "very high influence", the higher the value given, the greater the influence. The third part is the basic information of the subjects, including the age range, education, and the occupation.

\subsection{Research Subjects}

The step of survey data collection includes (1) recruited the members who have interested in the blockchain; (2) 
Taiwan Blockchain Expert Council educates and trains the members; (3) established the blockchain platform; (4) inviting participants to participate in training. Therefore, the questionnaires were filled in by ones who have knowledge and experience of blockchain. By doing that, occupation was not used to distinguish in this research survey. 62 participants who were recruited, trained, and prictical applied through the blockchain platform were the research subjects. The choice of the sample for this study was based on whether the subject had relevant professional background and rich blockchain knowledge, or whether he participated in the National Chung Hsing University blockchain platform. This survey was provided to understand the perceptions of consumers and microenterprises that have used blockchain.

\subsection{Data Analysis Method}

This study explores the micro-enterprise blockchains, and supplements the opinions of experts, scholars, practitioners, and consumers. DEMATEL and ISM are used to analyze the data of the questionnaire. The analysis steps of DEMATEL-ISM are as following (Lee \& Chen, 2017).

Step 1: Defining factors and establishing scales

Based on the literature review and expert interviews to integrate the degree of influence between the factors and establish five scales into "0", "1 "2", "3" and "4" respectively indicate "no influence" and "low influence", "Medium influence", "high influence" and "very high influence".

Step 2: DEMATEL- Creating Direct-Relation Matrix

The subjects judge the degree of influence between the two factors and fills in the corresponding scale, which produce a direct relationship matrix. If there are 20 subjects, 20 direct relationship matrices will be generated, and so on. In order to integrate the expert opinions, the arithmetic mean of the matrix generated by these subjects will establish a "direct relationship matrix" of average opinions. As shown in Equation 1, where $X_{-}$ij represents the extent to which factor $\mathrm{i}$ affects factor $\mathrm{j}$, and the partial value of the diagonal is zero.

$$
\mathrm{X}=\left[\begin{array}{ccc}
0 & \cdots & X_{i j} \\
\vdots & \ddots & \vdots \\
X_{i j} & \cdots & 0
\end{array}\right]
$$

Step 3: DEMATEL-establishing a standard Direct-Relation Matrix

The "Direct-Relation Matrix" obtained above, the maximum value in each column is summed and the reciprocal of the maximum value is the criterion value, and then multiply the criterion value by the direct-relation matrix. The calculation of "Standard Direct-Relation Matrix." is as shown in Equation 2.

$$
X^{\prime}=\frac{1}{\max _{1 \leq i \leq n} \sum_{j=1}^{n} X_{i j}} X,(i, j=1, \ldots, n)
$$

Step 4: DEMATEL-establishing Total-Relation Matrix

First, create the "identity matrix" as shown in Equation 3. Then subtract the "Standard Direct-Relation Matrix" from the "identity matrix" and calculate the "anti-matrix" of the result. Then use the "anti-matrix" minus the "identity matrix". The matrix can be used to find the " Total-Relation Matrix", the calculation is shown in Equation 4.

$$
\begin{gathered}
I=\left[\begin{array}{lll}
1 & 0 & 0 \\
0 & 1 & 0 \\
0 & 0 & 1
\end{array}\right] \\
T=\left(I-X^{\prime}\right)^{-1}-I
\end{gathered}
$$

Step 5: DEMATEL-set threshold

Although the "Total-Relation Matrix" can show the degree of mutual influence between different factors, it cannot see the influence of the factors themselves on themselves. Therefore, "Identity Matrix" can be expressed as the influence of the factors themselves on themselves, so "Total-Relation Matrix" is obtained. After the matrix, the "Total-Relation Matrix" created in step 4 and added the "Identity Matrix" to form the "whole Relation Matrix", and the threshold value can be set for screening. The value is greater than the threshold value indicates that the correlation is large. The value in the "Whole Relation Matrix" is less than the threshold value indicates the correlation is small and is replaced with 0 .

\section{Step 6: DEMATEL-Causal diagram}

After the threshold value is filtered, the value of each row of the matrix is collectively referred to as the D-value. The sum of the values of the columns is called the R-value. After calculating the $\mathrm{D}$-value and the R-value, each of the values can be further calculated prominence and relation. The centrality is D-value + R-value, indicating the core degree of the factor in the factor group. If the value is higher, it shows that the factor is higher in the factor group. The D-value - Rvalue indicates the degree of influence of the factor. If the value is "positive", it indicates that this factor has influence on other factors and is regarded as a causing factor, and called "cause". If the value is "negative", it indicates that this factor is easily affected by other factors and is regarded as a factor of influence, called "effect". 
In order to visualize the causal relationship between factors to assist decision makers in making appropriate decisions, the $D+R$ and $D-R$ values of each factor can be marked on the two-dimensional coordinates, the horizontal axis is $D+R$, and the vertical axis is $D-R$.

\section{Step 7: ISM-establishing Reachability Matrix}

This step is to replace the threshold value set in step 5, and replace the value with 1 in the "threshold whole Relation Matrix. The latter matrix is "Reachability Matrix".

Step 8: ISM-determine Antecedent Set and Intersection Set

The factor of $S_{i}$ in the matrix, the intersection of crossitem and the vertical-item value are selected as 1 , called the "Reachability Set", symbolized as $\mathrm{R} S_{i}$; then the vertical item and the horizontal item has an intersection value of 1 is selected as an Antecedent Set, represented by $\mathrm{A} S_{i}$; and the intersection of Antecedent Set and Intersection Set is Intersection Set, expressed as $\mathrm{RS}_{i} \cap \mathrm{A} S_{i}$. When the factors reachable the Reachability Set, Antecedent Set, Intersection Set, the hierarchical diagram can be drawn.

Step 9: ISM-Draw hierarchical diagram

As shown in Equation 5, select the same factors of the Reachability Set and Intersection Set. The selected factors are located at the top of the hierarchical diagram, indicating that the factor in this layer is only affected by the factors in other layers, and does not affect other layers; the next step is to remove the extracted factors and repeat Equation 5. And so on, until all the factors are extracted, and then draw the arrow according to the reachable matrix, the hierarchical diagram is established.

$$
\left\{S_{i} \mid R\left(S_{i}\right)=R\left(S_{i}\right) \cap A\left(S_{i}\right)\right\}
$$

\section{Research Results}

\subsection{Descriptive Statistics}

The data was collected from September October $1^{\text {st }}$ to November $15^{\text {th }}, 2018$ to understand the key success factors of blockchain platform for micro-enterprise. A total of 62 valid questionnaires were collected in this study. The demographic variables of the valid samples in this study can be divided into education and occupation. In educational level, "above the research institute" was the highest, with 29 persons, $46.8 \%$ of the valid samples. A total of 18 people education level was "university", $29.0 \%$ of the valid samples. In occupation, the number of subjects with "micro-enterprise operators" was $26,41.9 \%$ of the effective samples; followed by 21 people engaged in other occupations, $33.9 \%$ of the valid samples, shown in Table 2.

Table 2: Demographic

\begin{tabular}{|l|c|l|c|}
\hline \multicolumn{4}{|l|}{ Variables } \\
\hline Education & people & Occupations & people \\
\hline $\begin{array}{l}\text { Under elementary } \\
\text { school }\end{array}$ & 0 & Students & 12 \\
\hline Junior high school & 0 & Blockchain experts & 3 \\
\hline High school & 8 & Operators & 26 \\
\hline College & 7 & Other engineers, etc. & 21 \\
\hline $\begin{array}{l}\text { under graduated } \\
\text { school }\end{array}$ & 18 & & \\
\hline Graduated school & 29 & & \\
\hline
\end{tabular}

\subsection{DEMATEL-ISM Analysis Results}

In this study, 12 key success factors of blockchain platform for micro-enterprises were analyzed by DEMATELISM analysis. In order to simplify the complexity of the matrix, this study seeks expert advice to set the threshold to 0.55 for screening. The "screened overall relationship matrix" sums its rows and columns to calculate the $D$ and $R$ values. When the $D$ value and the $R$ value of the 12 key factors are calculated, the degree of prominence and the relationship of each factor can be further calculated, as shown in Table 3 The centrality is ( $D$ value $+R$ value), indicating the core value of the factor in the factor group. If the value is higher, it shows that the factor is more important in the overall factor evaluation. The centrality distribution obtained by the results of this study is from "13.20" to "2.51", in which the most important factor affecting the microenterprise blockchain is "13.20", which presents "trust" has the highest correlation with the other 11 factors. "Organizational adaptation" has the lowest centrality value, "2.51", indicating that "Organization adaptation" has the least correlation with the other 11 factors. The importance of the other 10 factors in the overall factor assessment is "Consistency" and "Safety and anti-counterfeiting", "Branded equity", "Transparency and clear", "traceability", "Consensus mechanism", "Sales growth", "Tracking", "International" and "Innovation Management".

On the other hand, the cause is $D$ value - $R$ value, indicating the influence of the factor or the degree of influence. If the value is "positive", it indicates that this factor has influence on other factors. The factor can be called "cause". If the value is "negative", it indicates that this factor is easily affected by other factors. It is regarded as a factor of influence and called "effect".

The distribution obtained from the cause of this study is from "1.12" to "-1.15". Among the key success factors, there 
are four factors classified as "cause group". These four key factors are "positive". The order of the cause value is "safety anti-counterfeiting", "traceability", "transparency and clear", "consistency", and the value of "security anti-counterfeiting" is "1.12". It is the most influential factor in the cause group for other factors; there are also four factors classified as "effect group". The four key factors are all "negative". The numerical order is in the order of "trust", "brand equity", "tracking", "sales growth", and the "sales growth" cause value is "-1.15", which is the most likely factor in the result group to be affected by other factors. The remaining three factors are "innovation management", "international" and "organizational adaptation". Since the three factors are all calculated as "zero", they are not classified as "cause groups" or "effect group" shows that these three factors do not affect other factors in the overall system and are not affected by other factors.

According to the "centrality" and "cause" calculated in Table 3, a causal map is drawn, as shown in Figure 1. In the causal map, the horizontal axis is $D+R$ (centrality), the vertical axis is $D-R$ (cause degree), and the "trust" is located at the rightmost position in the causal map, indicating that the core level is the highest, which affects the successful use of the block by the micro-enterprise. The upper right of the horizontal axis is the "cause group", which is regarded as the cause of the category, including "security anticounterfeiting", "traceability", "transparency clear", "consistency"; the lower half of the horizontal axis is the "effect group" It is considered to be a factor of influence, including "trust", "brand equity", "tracking", and "sales growth".

Table 3: Overall relationship matrix after threshold

\begin{tabular}{|c|c|c|c|c|}
\hline Factors & $\begin{array}{c}\text { D Influence } \\
\text { degree }\end{array}$ & $\begin{array}{c}\text { Be } \\
\text { influenced } \\
\text { degree }\end{array}$ & $\begin{array}{c}\text { D+R } \\
\text { Centrality }\end{array}$ & $\begin{array}{c}\text { D-R } \\
\text { Cause } \\
\text { degree }\end{array}$ \\
\hline Brand equity & 4.43 & 5.08 & 9.51 & -0.65 \\
\hline $\begin{array}{c}\text { Security anti- } \\
\text { counterfeiting }\end{array}$ & 5.65 & 4.52 & 10.17 & 1.12 \\
\hline Sale growth & 1.98 & 3.13 & 5.12 & -1.15 \\
\hline $\begin{array}{c}\text { Transparency } \\
\text { and clear }\end{array}$ & 4.45 & 4.40 & 8.85 & 0.06 \\
\hline Trust & 6.60 & 6.60 & 13.20 & 0.00 \\
\hline $\begin{array}{c}\text { Consensus } \\
\text { mechanism }\end{array}$ & 3.15 & 2.59 & 5.74 & 0.56 \\
\hline Traceability & 4.44 & 3.80 & 8.24 & 0.64 \\
\hline Consistency & 5.60 & 5.07 & 10.67 & 0.54 \\
\hline Tracking & 1.99 & 3.11 & 5.10 & -1.11 \\
\hline $\begin{array}{c}\text { Innovation } \\
\text { management }\end{array}$ & 1.34 & 1.34 & 2.68 & 0.00 \\
\hline International & 1.35 & 1.35 & 2.70 & 0.00 \\
\hline $\begin{array}{c}\text { Organizational } \\
\text { adaptation }\end{array}$ & 1.25 & 1.25 & 2.51 & 0.00 \\
\hline
\end{tabular}

Note: The cause value of "trust" is "-0.000140425", which is close to " 0 " and is represented by " 0 " in the table.

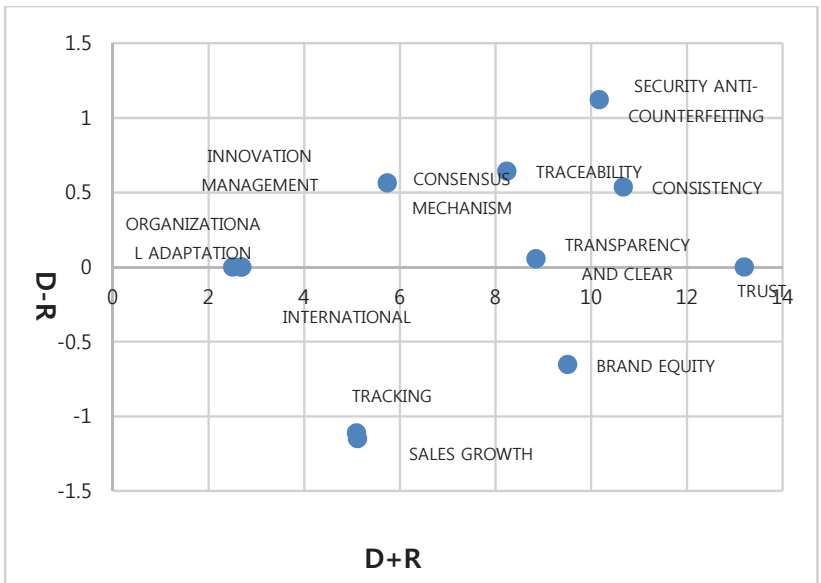

Figure 1: DEMATEL - Casual diagram

According to step 7, "threshold whole relation matrix" can be created a "reachable matrix". After the "reachable matrix" is obtained, the reachable set, 12 key success factors and the hierarchical association diagram of the study is constructed. The results obtained by the stratified extraction in this study divided the key factors for three layers. The third layer is the first extracted level, including "sales growth (S3)", "transparency clear (S4)", "trust (S5)", "tracking (S9)"; the second layer includes "brand equity (S1)", "security anticounterfeiting (S2)", "consistency (S8)", which found "brand equity (S1)", "security anti-counterfeiting (S2)", "consistency" (S8)". The three factors have a strong influence on each other. Therefore, in Figure 2, the three factors are selected as the same module; the first layer is the final extracted level, includes "consensus mechanism (S6)", "traceability (S7)"; and "Innovation management (S10)", "international (S11)", and "organization adaptation (S12)", shown in Table 3. Three factors do not affect other factors and is not affected by other factors, so three factors are not taken into account in drawing the Figure 2 ISM-level correlation diagram.

There are three layers of the key success factors of micro-enterprises blockchain hierarchical association diagram. The correlation between the factors is shown in Figure 2. The factors in the first layer are "consensus mechanism (S6)" and "traceability (S7)": "Consensus mechanism (S6)" will affect the second layer of "brand equity (S1)" and "consistency (S8)". It will also affect the third layer of "trust (S5)", shows that micro-enterprises can deliver high-quality services through the blockchain platform, enables consumers to reach a consensus on the company and helping companies to enhance their brand image and accumulate brand equity. At the same time, it promotes the transparency of internal production processes and achieves the consistency of internal production processes. 
Consumers will also have confidence in the company; "traceability (S7)" will affect the second layer; "brand equity (S1)", "security anti-counterfeiting (S2)", and "consistency (S8)" will also affect the third layer of "tracking transparency and clear (S4)" and "trust (S5)". The micro-enterprise uses the blockchain platform to provide detailed information.

The factors in the second layer are "brand equity (S1)", "security anti-counterfeiting (S2)", and "consistency (S8)". Three factors affect each other and represent the brands that micro-enterprises have accumulated through the blockchain platform. Equity will affect the information security of enterprises and the internal production process. If micro-enterprises improve the consistency and security of their internal production processes, they will also contribute to the improvement of brand equity. On the other hand, when the security and anti-counterfeiting of micro-enterprise is done well, it shows that the consistency of internal production processes is also done well. Through the microenterprises blockchain platform can enhance information security, anti-counterfeiting, improve the consistency of internal production processes, and the consistency of the internal production processes of the enterprise will also contribute to the improvement of security and anticounterfeiting.
In addition, "brand equity (S1)" will also affect "sales growth (S3)", "transparent clarity (S4)" and "trust (S5)" at the third layer when micro-enterprise uses blockchain platform to accumulate brand equity. Establish a good brand image for micro-enterprises, so that consumers can clearly understand the production process, and at the same time enable consumers to generate trust in the company and affect the sales volume of micro-enterprises; "security anticounterfeiting (S2)" will affect the third layer. "Sales growth (S3) ", "transparent clarity (S4)", "trust (S5)", and "tracking (S9)" show that when micro-enterprise uses blockchain platform to enhance the security of corporate information. The process continues to track the benefits while improving the security and anti-counterfeiting, it can also gain the trust of consumers, and also let consumers understand the internal production operations and affect the sales performance of the company; "consistency (S8)" will affect the third layer of "transparency clear (S4)", "trust (S5)", and "tracking (S9)" means that micro-enterprise can make internal production processes through the blockchain platform.

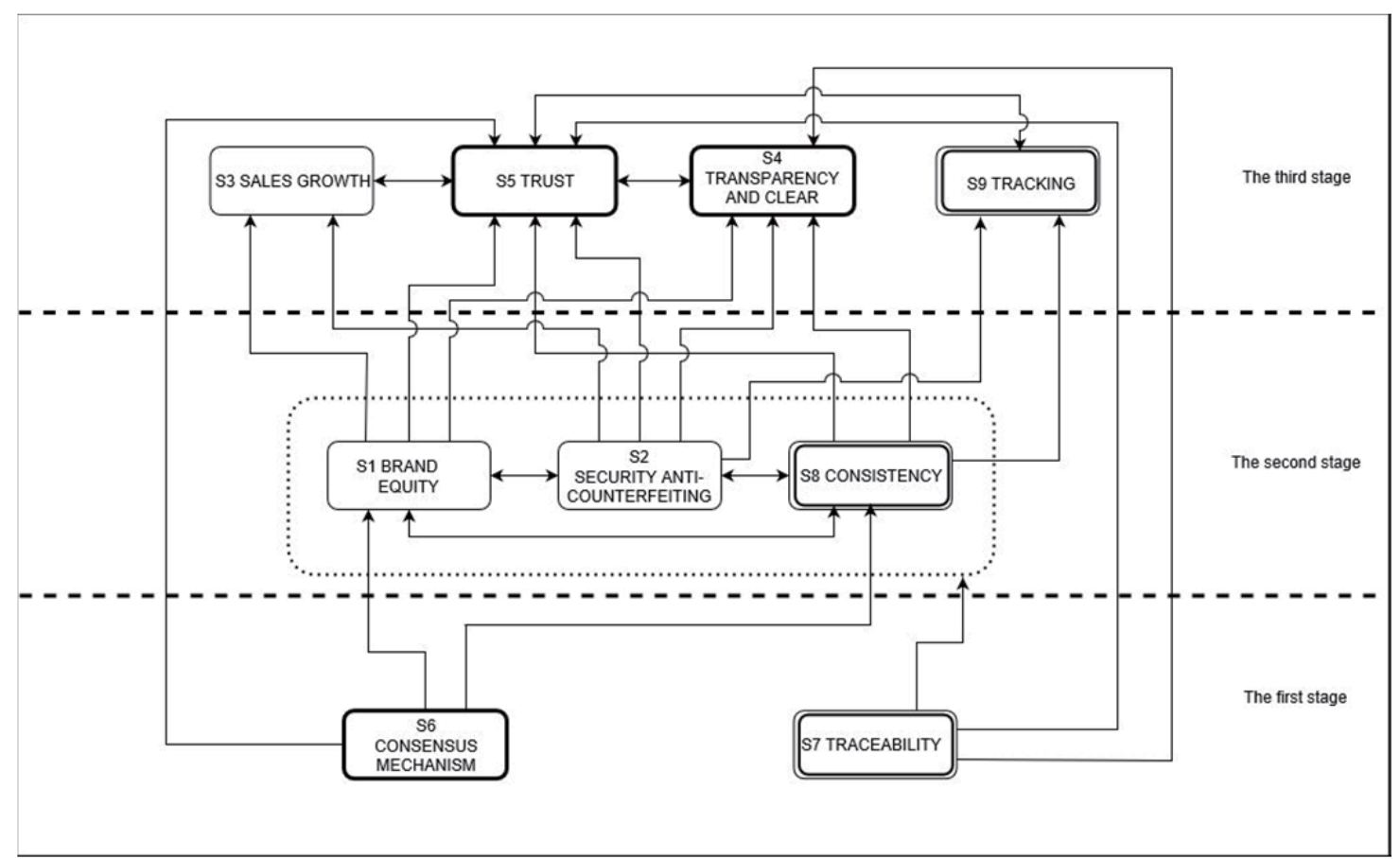

Note: "Innovation Management (S10), International (S11), Organizational adaptation (S12) do not related to other factors in the overall system.

Figure 2: ISM - Hierarchy diagram 
The last layer of factors are "sales growth (S3)", "transparency clear (S4)", "trust (S5)", "tracking (S9)", of which "trust (S5)" and "sales growth (S3)", "transparency clear (S4)", and "tracking (S9)" affect each other. It shows that when the sales of micro-enterprises grow, the consumers have a certain degree of trust in the enterprises. On the other hand, when the consumers trust the enterprise, it will affect the sales volume. When the consumers' trusts in the micro-enterprise are improved, the micro-enterprise internal production process is tracked clearly, the customers are satisfied with the information, and the relative trust is also improved. Therefore, the micro-enterprise can enhance the customer's trust through the blockchain platform when the internal process tracking of the micro-enterprise is clear, the customers' trusts will be improved. Through the blockchain platform, micro-enterprises can make customers' trust the company, understand the information exposed by the companies, and provide transparent information to enhance consumers' trusts in micro-enterprises.

In Figure 2 the results of the study show that the first steps S6 and S7 is the foundation and must be done first. The second step is S6 vs S1 and S8, can be performed with S5 at the same time, but the foundation of S5 is not stable at this time. S7 and S1, S2, and S8 are associated with each other, and S5 and S4 can also be performed at the same time. At this time, the foundation of S5 and S4 are not stable. Other results are analogized by the diagram.

\section{Conclusions}

A micro-enterprise is established without investing too much technology and capital. Although the entry threshold is low, the survival of the company is not easy to maintain. From the perspective of the overall enterprise, BSC can be used as a performance measurement tool for enterprise information technology, used to define the company's tasks and strategies to create competitive advantages for enterprises, and assisting companies to successfully introduce innovative technologies. Based on the four perspectives of finance, customers, internal processes, and learning growth, BSC is a comprehensive and integrated measurement tool, 12 key success factors of blockchain platform for micro-enterprise include "brand equity", "security and security", "sales growth", "transparency and clear", "trust", "consensus mechanism", "traceability", "consistency", "tracking", "innovation management", "international" and "organizational adaptation" can be followed as a micro-enterprise blockchains.

This study explores the correlation between these key factors through a hybrid decision-making laboratory analysis and an interpretive structural model. It is found that "trust" plays a very important role when micro-enterprise introduces blockchain technology. Through the blockchain platform, micro-enterprise can make consumers resonate with the company, and the internal production process will be exposed to the consistency of the production process due to the disclosure of information. The consumers also have the information transparency of the enterprise and the production history of the enterprise. On the other hand, some studies mention that consumers' trust companies to express those consumers believe that companies can provide long-term benefits and good services to consumers. Consumers will be willing to establish long-term relationships with companies because they trust companies, and blockchain technology allows consumers to trust the authenticity of corporate information and help consumers build good relationships with microenterprises.

Therefore, when micro-enterprise ensures the authenticity of corporate data through the blockchain platform, providing consumers with better service will help consumers resonate with the company, affect the brand image of the company, and accumulate brand assets. Consumers' purchase decisions and demand are affected by the brand to a certain extent. Therefore, it can be seen from the results of this study that micro-enterprises can accumulate corporate brand assets through blockchain platform.

In the results of this study, the three key factors of "innovation management", "international", and "organizational adaptation" are less important in the overall system and are not related to other factors. We explore the possible reasons for micro-enterprises at the beginning of the business; it should pay more attention to innovation management. After starting the business, there are no much time and effort to focus on innovation management. On the other hand, because micro-enterprise organizations are small in scale, there is no problem of organizational adaptation and international ambition.

It is worthwhile to continue to do the research in the future, but the limitations for the research is if the platform is really established, how can the participants insert some important information systematically should be cooperate with the technical system. The contribution of this research is able to expand the function of the micro-enterprise blockchain platform, provide a case study of blockchain as a reference, and provide a reference for micro-enterprises to reduce costs, improve the production activities to open up markets for enterprises and attract more consumers.

\section{References}

Abeyratne, S. A., \& Monfared, R. P. (2016). Blockchain ready manufacturing supply chain using distributed ledger. 
International Journal of Renewable Energy Technology, 5, 1-6.

Acuña-Carvajal, F., Pinto-Tarazona, L., López-Ospina, H., Barros-Castro, R., Quezada, L., \& Palacio, K. (2019). An integrated method to plan, structure and validate a business strategy using fuzzy DEMATEL and the balanced scorecar. Expert Systems with Applications, 122(15), 351-368.

Addae, B. A., Zhang, L., Zhou, P., \& Wang, F. (2019). Analyzing barriers of Smart Energy City in Accra with twostep fuzzy DEMATEL. Cities, 89, 218-227.

Buehrer, R. E., Senecal, S., \& Pullins, E. B. (2005). Sales Force Technology Usage-Reasons, Barriers, and Support: An Exploratory Investigation. Industrial Marketing Management, 34(4), 389-398.

Basso, A., Casarin, F., \& Funari, S. (2018). 'How well is the museum performing? A joint use of DEA and BSC to measure the performance of museums. Omega, 81, 6784.

Buck, J. (2017). Bringing Blockchain Technology to ECommerce: Current Trends. The Coin Telegraph. Retrieved June 10, 2019 from https://cointelegraph.com/news/bringing-blockchaintechnology-to-e-commerce-current-trends

Chen, J. T., \& Tsai, T. C. (2012). The Lending Benchmarks and Lending Policies of SME Loans: Evidence from Cases of Loans under Package Credit Guarantee. Taiwan Academy of Banking and Finance, 13(1), 25-55.

Chin, O., \& Nor, M. M. (2016). 'Does The Micro Financing Term Dictate The Performance of Micro Enterprises?' Procedia Economics and Finance, 35, 281-286.

Chang, P. C. (2003). Analysis of competitive advantages of enterprises created by information technology. Journal of Internet Technology, 4(1), 19-25.

Choi, J., Seol, H., Lee, S., Cho, H., \& Park, Y. (2008). Customer satisfaction factors of mobile commerce in Korea. Internet Research, 18(3), 313-335.

Dinh, T. T. A., Wang, J., Chen, G., Liu, R., Ooi, B. C., \& Tan, K. L., (2017). Blockbench: A framework for analyzing private blockchains. Proceedings of the 2017 ACM International Conference on Management of Data, 10851100.

Gabus, A., \& Fontela, E. (1973). Perceptions of the World Problematique: Communication Procedure. Communicating with those Bearing Collective Responsibility (DEMATEL), Battelle Geneva Research Center, Switzerland, Geneva.

Huang, I. P. (2011). Empirical research on brand asset dimension based on consumer perspective. Journal of Zaozhuang University, 28(3), 60-64.
Hsu, C. I., \& Huang, H. J. (2011). Research on female micro-entrepreneurship and multi evaluation. East Asia Review, 47(2), 119-137.

Hany F., Atlam, G., \& Wills, B. (2018). Technical aspects of blockchain and loT. Advances in Computers, 1, 1-39.

Jharkharia, S., \& Shankar, R. (2004). IT enablement of supply chains: Modeling the enablers. International. Journal of Productivity and Performance Management, 53(8), 700-712.

Ko, C. H. (2019). Global retail industry development trends and transformation strategies. Deloitte. Retrieved February 5, 2019, from https://www2.deloitte.com/ tw/tc/pages/consumer-business/articles/global-retailingdevelopment.html

Kuo, T. C., Ma, H. Y., Huang, S. H., Hu, A. H., \& Huang, C. S. (2010). Barrier analysis for product service system using interpretive structural model. The International Journal of Advanced Manufacturing Technology, 49(1-4), 407-417.

Kumar, A., \& Dixit, G. (2018). 'An analysis of barriers affecting the implementation of e-waste management practices in India: A novel ISM-DEMATEL approach'. Sustainable Production and Consumption, 14, 36-52.

Kaplan, R., \& Norton, D. (1996). Using the Balanced Scorecard as A Strategic Management System, Harvard Business Review, 74(1), 75-85.

Lin, S. B., Lee, Y. C., Chao, Y. H., \& Chang, Y. T. (2010). Integrate DEMATEL and ISM Approaches in Connector Design. Chung Hua Journal of Management, 11(2), 52-74.

Lee, T. R., \& Chen, H. Yu. (2017). Analysis on SME Transformation and Internationalization by Combining BSC with Hybrid-Expert Based ISM and DEMATEL Models: The Case of a Taiwanese (Master thesis). Taichung, Taiwan: National Chung-Hsing University.

Li, H., Tian, H., Zhang, F., \& He, J. (2019). Blockchainbased searchable symmetric encryption scheme. Computers \& Electrical Engineering, 73, 32-45.

Larimer, D. (2014). Delegated Proof-of-Stake (DPOS). Retrieved June 10, 2019 from https://bitcointalk.org/index.php?topic $=558316.0$

Muzammal, M., Qu, Q., \& Nasrulin, B. (2019). Renovating blockchain with distributed databases: An open source system. Future Generation Computer Systems, 90, 105117.

Ministry of Economic Affairs, R.O.C. (2015). Tandard for identifying small and medium-sized enterprises. Rootlaw. Retrieved February 5, 2019 from http://www.rootlaw.com.tw/LawArticle.aspx?LawID=A0401 00160000300-1040330

Modak, M., Ghosh, K. K., \& Pathak, K. (2018). A BSC-ANP approach to organizational outsourcing decision support- 
A case study. Journal of Business Research. https://doi.org/10.1016/j.jbusres.2018.01.040.

Pilkington, M. (2016). Blockchain technology: Principles and applications. Research Handbook on Digital Transformations. Cheltenham, England: Edward Elgar.

Patil, S., \& Kant, R. (2016). Evaluating the impact of Knowledge Management adoption on Supply Chain performance by BSC-FANP approach: An empirical case study'. Tékhne, 14(1), 52-74.

Pla-Barber, J., \& Alegre, J. (2014). The role of knowledge and learning in internationalization. International Business Review, 1(23), 1-3.

Quezada, L. E., López-Ospina, H. A.,Palominos, P. I., \& Oddershede, A. M. (2018). Identifying causal relationships in strategy maps using ANP and DEMATEL. Computers and Industrial Engineering, 118(10), 170-179.

Romano, D., \& Schmid, G. (2017). Beyond Bitcoin: A Critical Look at Blockchain-Based Systems. Cryptography, 1(2), 15. https://doi.org/10.3390/cryptography1020015

Shrestha, R., Bajracharya, R., Shrestha., A. P., \& Nam., S. Y. (2019). A new-type of blockchain for secure message exchange in VANET. Digital Communications and Networks. https://doi.org/10.1016/j.dcan.2019.04.003

Tsai, S. B. (2018). Using the DEMATEL model to explore the job satisfaction of research and development professionals in china's photovoltaic cell industry. Renewable and Sustainable Energy Reviews, 81, 62-68.

Trinh, L. Q., \& Doan, H. T. T. (2018). Internationalization and the growth of Vietnamese micro, small, and medium sized enterprises: Evidence from panel quantile regression. Journal of Asian Economics, 55, 71-83.

Tian, Z., Li, M., Qiu, M., Sun, Y., \& Su, S. (2019). Block-DEF: A secure digital evidence framework using blockchain.
Information Sciences, 491, 151-165. https://doi.org/10.1016/j.ins.2019.04.011

Taylor, P. J., Dargahi, T., Dehghantanha, A., Parizi, R. M., \& Choo, K. R. (2019). A systematic literature review of blockchain cyber security. Digital Communications and Networks. https://doi.org/10.1016/j.dcan.2019.01.005

Viriyasitavat, W., \& Hoonsopon, D. (2019). Blockchain characteristics and consensus in modern business processes. Journal of Industrial Information Integration, 13, 32-39. https://doi.org/10.1016/j.jii.2018.07.004

Wang, X., Zha, X., Ni, W., Liu, R. P., Guo, Y. J., Niu, X., \& Zheng, K. (2019). Survey on blockchain for Internet of Things. Computer Communications, 136, 10-29.

Wolco, P., Qureshi, S. \& Kamal, M. (2007). An Information Technology Therapy Approach to Micro-enterprise Adoption of ICTS, Reaching New Heights. Paper presented at 13th Americas Conference on Information Systems, AMCIS 2007, Keystone, Colorado, USA. Retrieved from http://aisel.aisnet.org/amcis2007/73

Wang, J. F., \& Wang, J. J. (2011). A review of theories on Micro-enterprises. Hohhot, China: Inner Mongolia Finance and Economics College.

Wang, S. W. (2011). Micro-enterprise and entrepreneurship counseling policy in Taiwan, Economic Outlook Bimonthly, 133, 29-33.

Yang, C. H., \& Tso, J. L. (2018). The Decentralized Banking KYC Platform Based on Blockchain. Communications of the CCISA, 4(4), 1-14.

Ziyae, B., Sajadi, S. M., \& Mobaraki, M. H. (2014). The deployment and internationalization speed of e-business in the digital entrepreneurship era. Journal of Global Entrepreneurship Research, 4(15), 1-11. DOI: https://doi.org/10.1186/s40497-014-0015-2 